\author{
Martin Pavlík, Martin Lukáčik \\ University of Economics in Bratislava \\ e-mails:mpavlik10@gmail.com; martin.lukacik@euba.sk
}

\author{
Grzegorz Michalski \\ Wrocław University of Economics \\ e-mail: grzegorz.michalski@ue.wroc.pl
}

\title{
SOFTWARE FOR THE DEMONSTRATION OF THE FUNDAMENTS OF PORTFOLIO SELECTION ${ }^{1}$
}

\begin{abstract}
Summary: Financial liquidity interconnections are close to be a portfolio investment problem. The following article is a result of the Slovak-Polish cooperation, between partners from University of Economics in Bratislava and Wroclaw University of Economics. We have created a set of three programs in MS Excel which calculate the approximation of the border of the investment opportunities. The applications are continually developed. All programs are written in VBA for Excel. The following article introduces the second and the third program in which we have coded the fundaments of the portfolio selection to the VBA Excel. Their names are FINV and IDPORT. The FINV calculates the border of investment opportunities by using matrix algebra. FINV works with the enabled short sales. IDPORT calculates the border of investment opportunities by using SOLVER, which is the optimization library. The software has many settings which will be described in the article. It demonstrates the fundaments of the theory of investment portfolio and it is suitable for the teaching purposes at this stage of the development.
\end{abstract}

Keywords: Markowitz diversification, VBA, Visual Basic for Application, Excel, risk, return, standard deviation, Jarque-Bera statistics.

DOI: $10.15611 /$ ekt.2014.3.09

\section{Introduction}

Investments that could be considered as a portfolio are a subject of a financial liquidity management case. Such a kind of investments enterprises is created due to

\footnotetext{
${ }^{1}$ Acknowledgement: Research project was financed by National Science Centre granted according decision nr DEC-2014/13/B/HS4/00192, the paper is part of the monothematic cycle about organization flexibility, liquidity and slvency relations with efficiency of the small and medium enterprises maintaning full operating cycle.
} 
investing money in current assets known also as working capital [Michalski 2012]. The consequences of managerial decisions at the current assets investments level impact the cash flows and the financial position of an enterprise. There are two kinds of current assets investment influences: positive, linked with cash revenues stimulation and a decreasing level of risk, and negative, linked with increasing cash expenses [Keynes 1936; Michalski 2014]. Current assets maintained in a firm are linked with portfolio effects. Financial liquidity decisions could be considered from three perspectives: from the point of view of the intrinsic value of financial liquidity compared with market value of liquidity, from the point of view of risk sensitivity of current assets investments consequences and from the point of view of the behavioral finance approach to financial liquidity investments. Portfolio choice problems concern all of them but here we concentrate on risk sensitivity on the point of view of current assets investments consequences. Financial liquidity investments in enterprises are made for safety purposes. Without them there is no possibility to safely manage the operational cycle of an enterprise. The operational cycle is realized as a main process in enterprise value creation, during which value is added through collecting raw materials, next - thanks to using enterprise fixed assets with energy and the intellectual capital of an enterprise - raw materials change into final production. Finished goods are offered to enterprise clients, and the way they are offered is also an opportunity to create additional value. Current assets are important part of all the steps in the operational cycle. The lack of current assets at any time of operational cycle realization could stop value creation and is linked with possible long term consequences. The following article is a result of the SlovakPolish cooperation. We have created a set of three programs in MS Excel which calculate the approximation of the border of investment opportunities. Applications are continuously developed. All programs are written in VBA for Excel. The present article introduces the second and the third program, which are able to find the border of investment opportunities by solving optimization nonlinear tasks.

\section{Theoretical introduction}

\subsection{Expected return and risk measures of shares}

The Markowitz [1997] diversification is found to be the start of the modern theory of an investment portfolio. Markowitz [1997] suggested measures for estimating the risk of a portfolio and its expected return. Risk was measured as a standard deviation and expected return as a arithmetical mean.

Expected return of a single share:

$$
E(R)=\sum_{k=1}^{n} p_{k} R_{k},
$$

where: $R_{k}$ is a random variable, $p_{k}$ is the probability of observing $R_{k}$. 
The risk of a single share: $\sigma^{2}(R)=E\left[(R-E(R))^{2}\right]=\sum_{k=1}^{n} p_{k}\left(R_{k}-E(R)\right)^{2}, \sigma(R)=$ $\sqrt{\sigma^{2}(R)}$.

Arithmetical mean and standard deviation are the measures which Markowitz [1997] started with. Other measures were developed afterwards.

The relatively new risk measure is Value at Risk $(\mathrm{VaR})$. $\mathrm{VaR}$ is $0.01 ; 0.05$ or 0.1 percentile of the loss calculated from the random distribution of a share or investment portfolio. The formula for $\operatorname{VaR}_{q}$ is :

$$
\operatorname{VaR}_{\alpha}=V_{0}\left(z_{\alpha} \sigma(R)+E(R)\right),
$$

where $z_{\alpha}$ is $\alpha$ quantile of the normal distribution and $V_{0}$ is the initial investment.

\subsection{Expected return and risk measures of an investment portfolio}

The expected return of an investment portfolio is calculated as:

$$
E\left(R_{p}\right)=E\left(\sum_{k=1}^{n} w_{k} \cdot R_{k}\right)=\sum_{k=1}^{n} w_{k} E\left(R_{k}\right) \quad \sum_{k=1}^{n} w_{k}=1,
$$

where: $w_{k}$ are the weights of individual shares. Weights can be positive or negative in case short sales are enabled. Disabled short sales means that weights are nonnegative. The risk of an investment portfolio in case the risk measure was chosen as the standard deviation is calculated as:

$$
\sigma^{2}\left(R_{p}\right)=\sum_{k=1}^{n} w_{k}^{2} \cdot \sigma_{k}^{2}+2 \sum_{k=1}^{n} \sum_{l>k} w_{k} w_{l} \sigma_{k l}
$$

or

$$
\sigma_{p}^{2}=\mathbf{w}^{T} \cdot \mathbf{C} \cdot \mathbf{w}
$$

where $\mathbf{C}$ is a covariance matrix.

$\mathrm{VaR}$ calculation is different:

$$
\operatorname{VaR}_{\alpha}=V_{0}\left(z_{\alpha} \sigma\left(R_{p}\right)+E\left(R_{p}\right)\right),
$$

where $z_{\alpha}$ is $\alpha$-quantile of the normal distribution and $V_{0}$ is initial investment.

Creating the border of the investment opportunities is a nonlinear programming problem:

$$
\begin{aligned}
& \min \sigma^{2}\left(R_{p}\right) \\
& E\left(R_{p}\right)=E_{p},
\end{aligned}
$$




$$
\begin{gathered}
\sum w_{i}=1, \\
w_{i} \geq 0
\end{gathered}
$$

In case short sales are enabled, constraint (c) is not active. The nonlinear task can be solved directly for enabled short sales. In that case the weights are:

$$
w=\Sigma^{-1}[\mu 1] \cdot A^{-1}\left[\begin{array}{c}
\mu_{p} \\
1
\end{array}\right],
$$

where $A=\left[\begin{array}{ll}\mu^{T} \cdot \Sigma^{-1} \cdot \mu & \mu^{T} \cdot \Sigma^{-1} \cdot \mathbf{1} \\ \mu^{T} . \Sigma^{-1} \cdot \mathbf{1} & \mathbf{1}^{T} \cdot \Sigma^{-1} \cdot \mathbf{1}\end{array}\right]$

$w$ is a vector of weights, $\mu$ is a vector of individual returns, $r_{f}$ is a riskless rate, $\sum$ is a covariance matrix and $\mu_{p}$ is a portfolio return.

\subsection{The tangency portfolio}

The tangency portfolio is a portfolio which maximizes the Sharpe's ratio. It is a nonlinear programming task where:

$$
\begin{gathered}
\max \frac{E(R p)-R f}{\sigma(R p)}, \\
\sum w_{i}=1, \\
w_{i} \geq 0 .
\end{gathered}
$$

It can be derived that for enabled short sales that the weights are:

$$
w=\frac{\Sigma^{-1}\left(\mu-r_{f} \cdot \mathbf{1}\right)}{\mathbf{1}^{T} \cdot \Sigma^{-1}\left(\mu-r_{f} \cdot \mathbf{1}\right)},
$$

where $w$ is the vector of weights, $\mu$ is the vector of individual returns, $r_{f}$ is a riskless rate and $\sum$ is a covariance matrix.

\subsection{The global minimum variance portfolio}

The global minimum variance portfolio is a portfolio with the smallest possible variance. The weights of the global minimum variance portfolio can be derived as:

$$
w=\frac{\Sigma^{-1} \cdot \mathbf{1}}{\mathbf{1}^{T} \Sigma^{-1} \cdot \mathbf{1}}
$$

Derivation (3) works just for portfolios with short sales. The global minimum variance portfolio without short sales is a nonlinear programming task which has to be solved numerically through optimization algorithms (SOLVER library). 


\subsection{Expected return and its distribution}

One of the assumptions of the investment portfolio theory is that the distribution of returns is a normal distribution. We test every share and every portfolio with the Jarque-Berra test, which tests whether the tested distribution is normal or not. It is a test which is based on testing skewness and kurtosis. Normal distribution has skewness equal to zero and kurtosis is equal to 3 . That is why the JB test tells that distribution is normal when Jarque-Bera statistics is close to zero. Jarque-Bera statistics has $\chi^{2}$ distribution with the two degrees of freedom. $q_{0.95}^{\chi^{2}(2)} \approx 6$. If JarqueBera statistics is smaller than 6 , we accept $\mathrm{H}_{0}$ that the observed random variable has independent and identically distributed normal distribution.

$$
\begin{gathered}
J B=\frac{T}{6}\left(\widehat{\text { skew }}^{2}+\frac{(\widehat{\text { kurt }}-3)^{2}}{4}\right), \\
\widehat{\text { skew }}=\frac{1}{T-1} \sum_{t=1}^{T} \frac{\left(x_{t}-\bar{x}\right)^{3}}{s_{x}^{3}}, \\
\widehat{\text { kurt }}=\frac{1}{T-1} \sum_{t=1}^{T} \frac{\left(x_{t}-\bar{x}\right)^{4}}{s_{x}^{4}} .
\end{gathered}
$$

\section{The presentation of the functions and operations of the programs FINV and IDPORT}

\subsection{IDPORT software manual}

IDPORT is software which has been written in VBA in Excel. It uses SOLVER library for solving nonlinear programming tasks. It contains 6 sheets called: Inputs, Risk and Return, Correlation Coefficients, Results, Solver Solve and Graph. It also contains one hidden sheet.

The sheet Inputs is a sheet which contains inputs as returns of individual shares for particular periods of time. It contains also a MENU button which opens forms which are used for the interaction between the user and the software. The sheet Inputs contains also a simple protocol about settings which were used for calculations.

Figure 1 shows the parts of the sheet Input. A is a simple protocol about calculation settings. $\mathbf{B}$ is a MENU button which opens the dialog form. $\mathbf{C}$ is calculation time which shows the beginning of calculations, the end of calculation and the difference between those two. D is a simple protocol about the SOLVER settings which were used for calculations. $\mathbf{E}$ is a column where users put the names of shares. $\mathbf{F}$ is a table where users put the returns of individual shares for particular time periods.

Figure 2 shows the part of the Return and Risk sheet. A is for names of shares. B is a column where individual returns are computed with the riskless rate at the top of it. $\mathbf{C}$ is for Jarque-Bera statistics results. All the results which are higher than 5.9925 are in the cell with the red background. If Active Management was used, the type of 


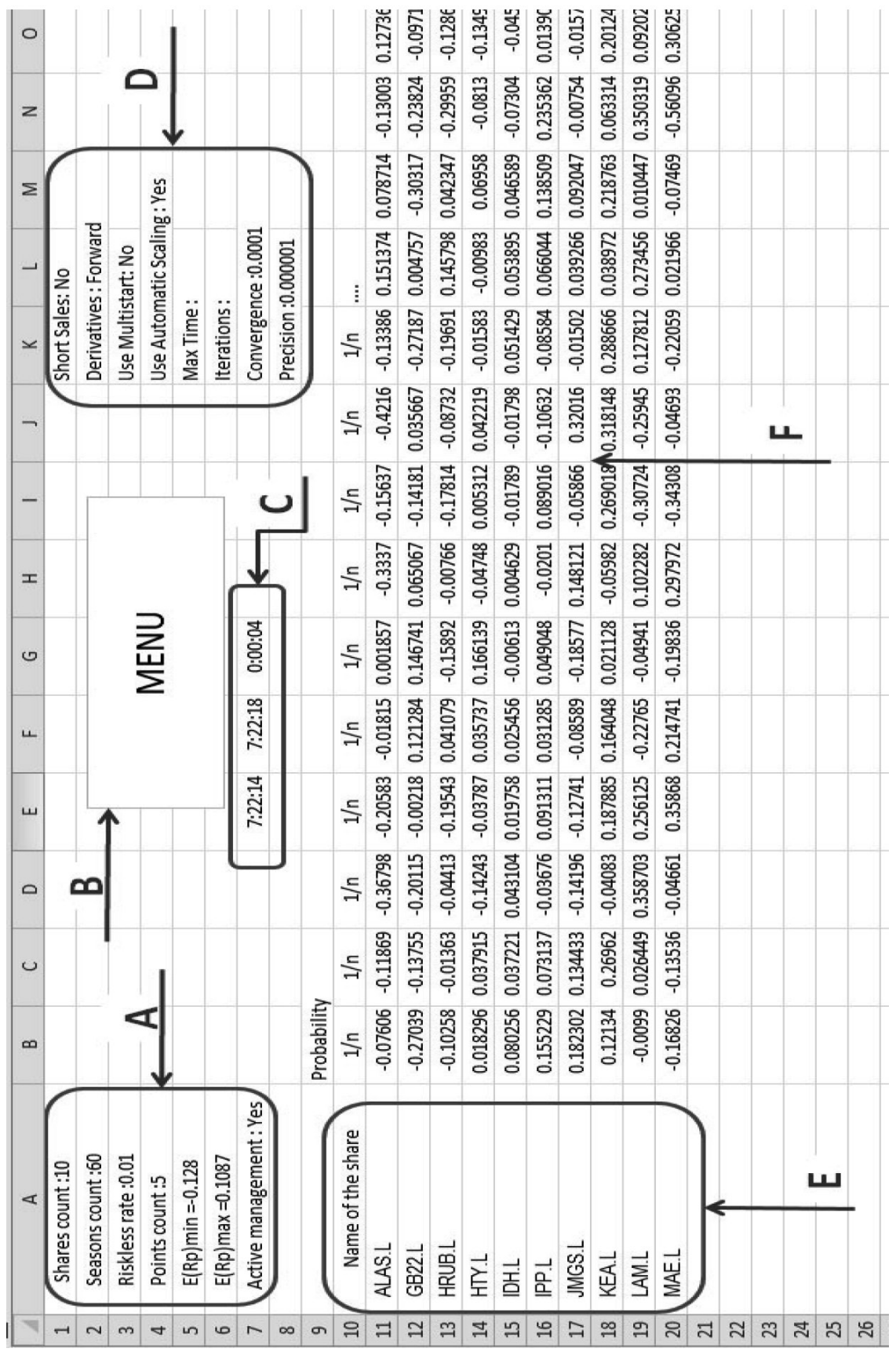

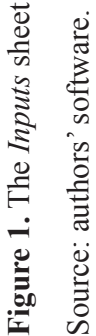




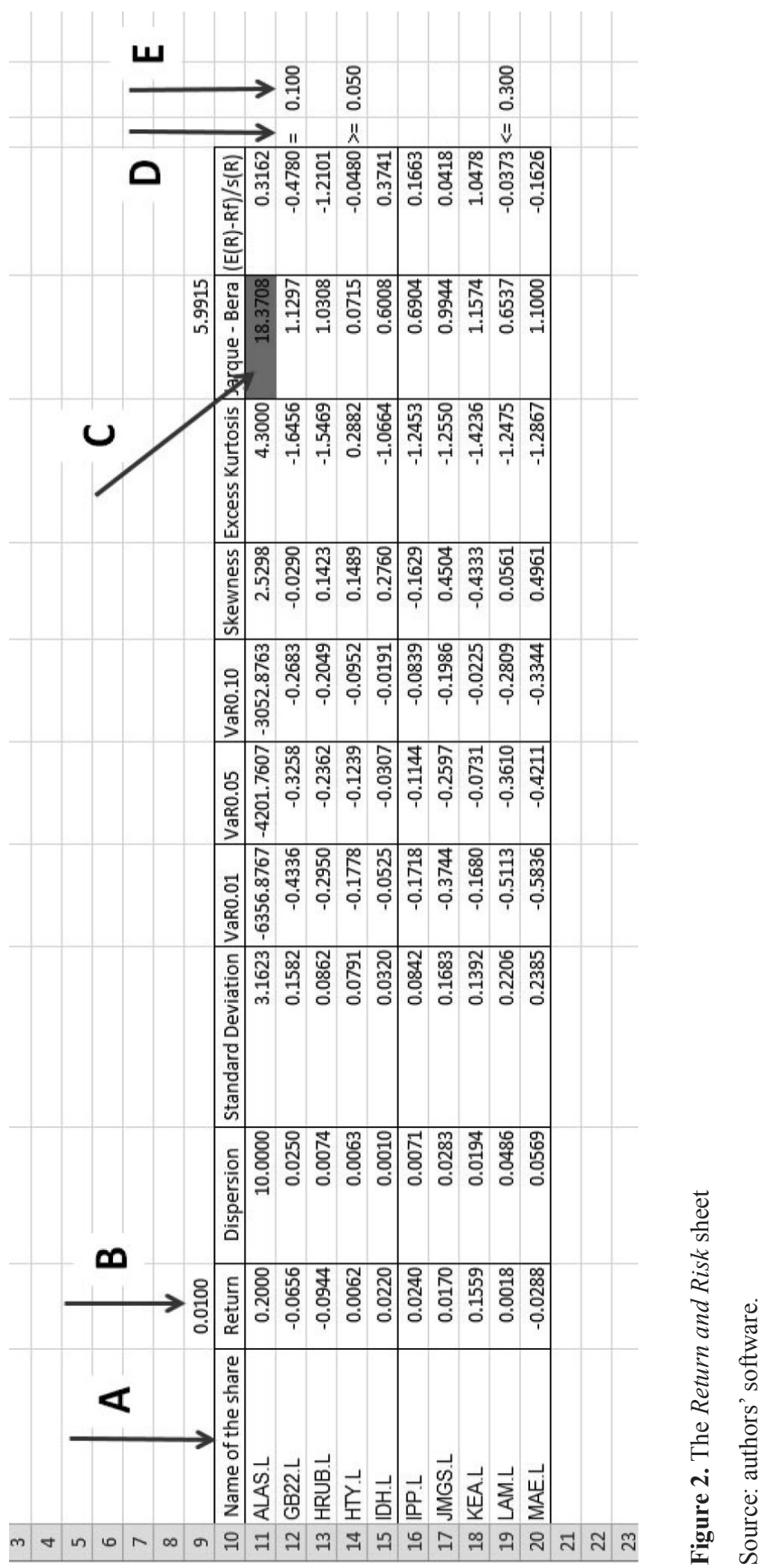




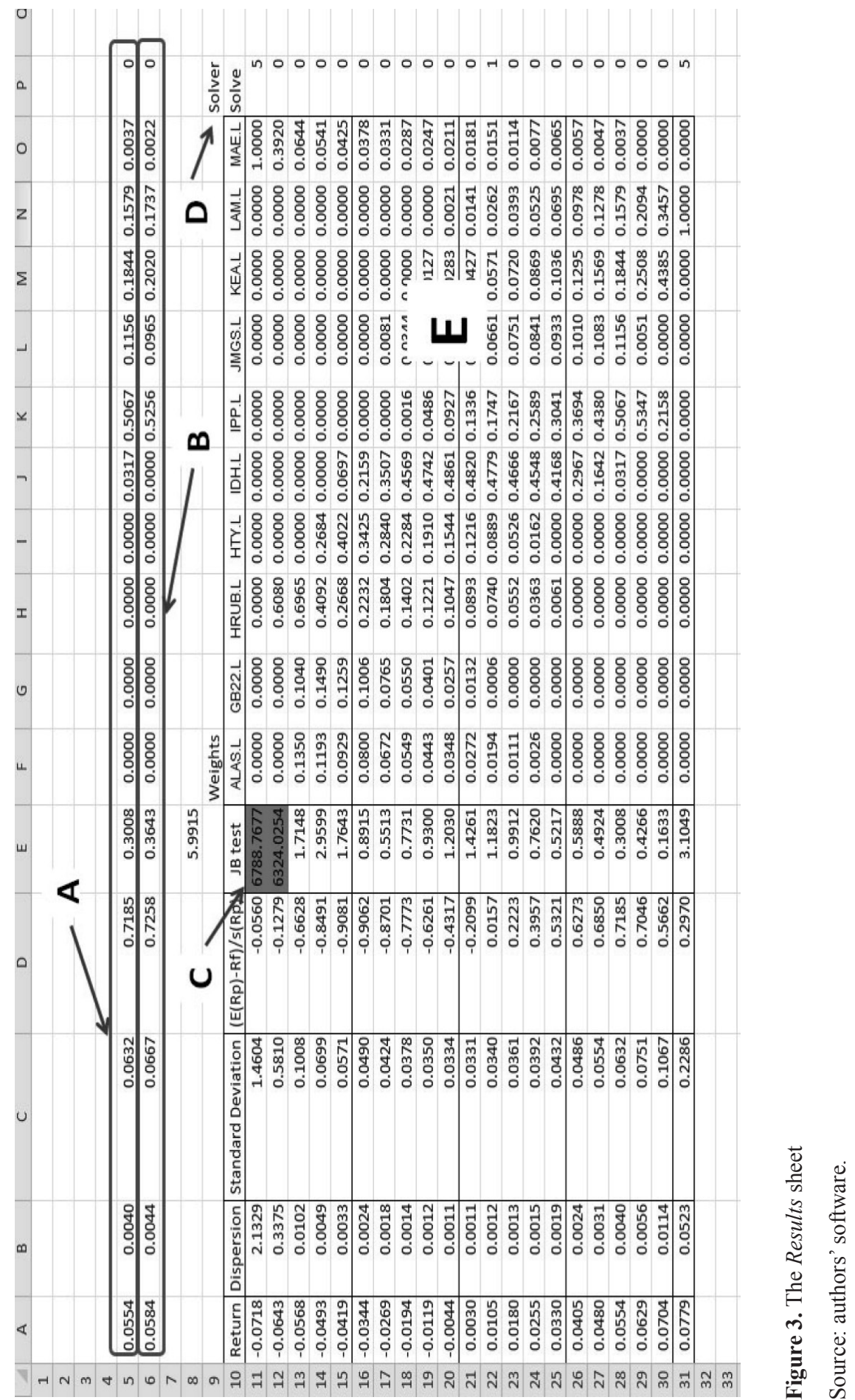


the constraint is in $\mathbf{D}$ and the value of the constraint is in $\mathbf{E}$. The Return and Risk sheet contains also risk calculations such as standard deviation and $\mathrm{VaR}$. It contains also calculation of skewness and excess Kurtosis. In case the user chose a riskless rate, the Return and Risk sheet contains also Sharpe's ratio. The Correlation Coefficients sheet contains correlation coefficients.

Figure 3 shows the Results sheet. A shows the tangency portfolio which was chosen from the list of calculated portfolios according to the highest Sharpe's ratio. B shows the tangency portfolio which is a result of a separate maximization nonlinear programming task. $\mathbf{C}$ is a column which contains Jarque-Bera test results. Those results which are higher than 5.99 are in red background. D is an Solver library output which tells us how the optimization task finished. The key to that value is the Solver Solve sheet. $\mathbf{E}$ is a list of weights which were assigned to particular shares.

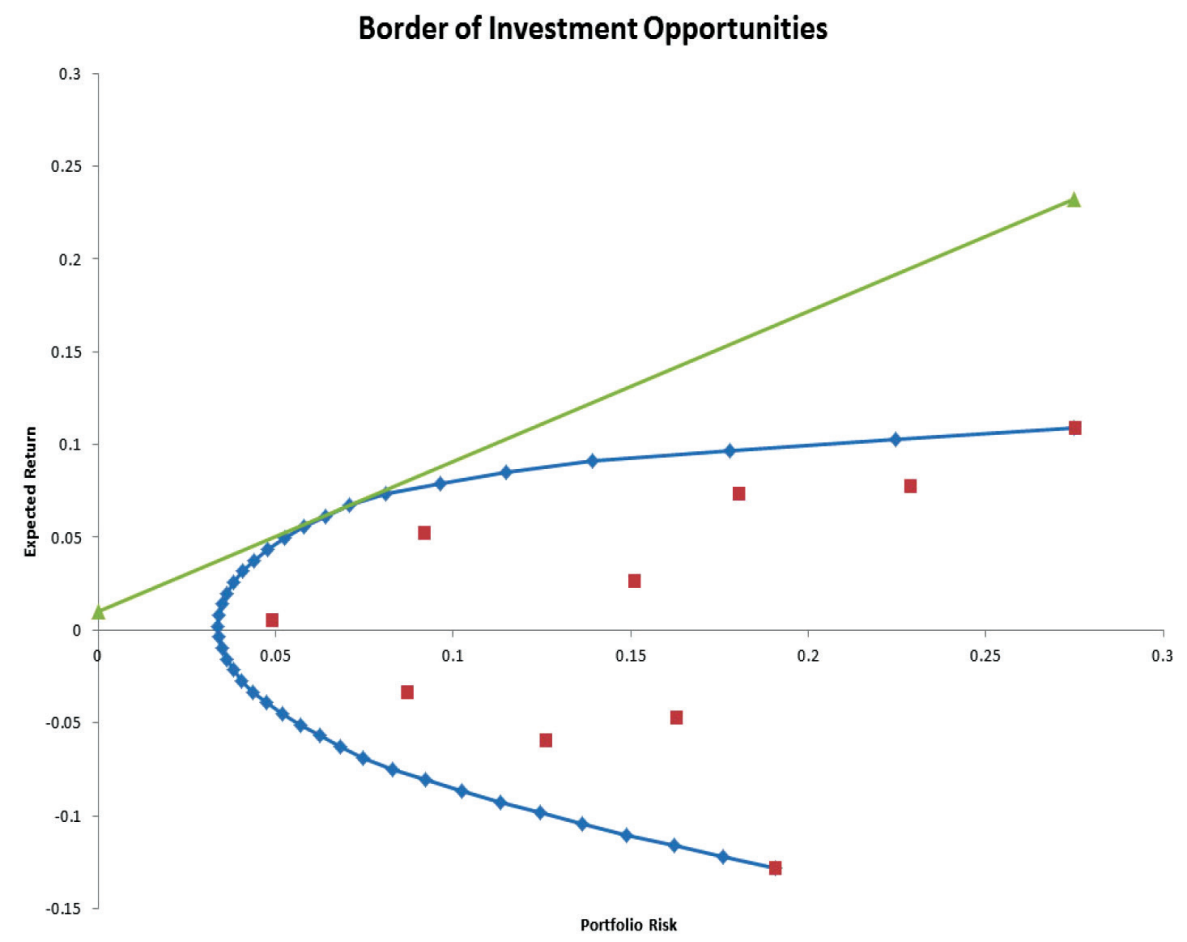

Figure 4. The Graph sheet

Source: authors' software.

Figure 4 shows the Graph sheet. It is a graph which shows the border of investment opportunities. The red dots are single shares in return risk space.

Figures 5 and 6 show the menu. Basic Settings are used for settings of Points Count, which is a number of nonlinear programming tasks. Riskless Rate is used for 
setting a riskless rate and the user has also an option not to set a riskless rate at all. Limits are used for setting zoom on the expected return axis. Active Management gives the user an option to back or penalize particular shares. This option adds an extra constraint to nonlinear programming tasks. Solver Settings is used for setting the solver library. Calculations use the default settings and if the user wants different settings, this has to be set here.

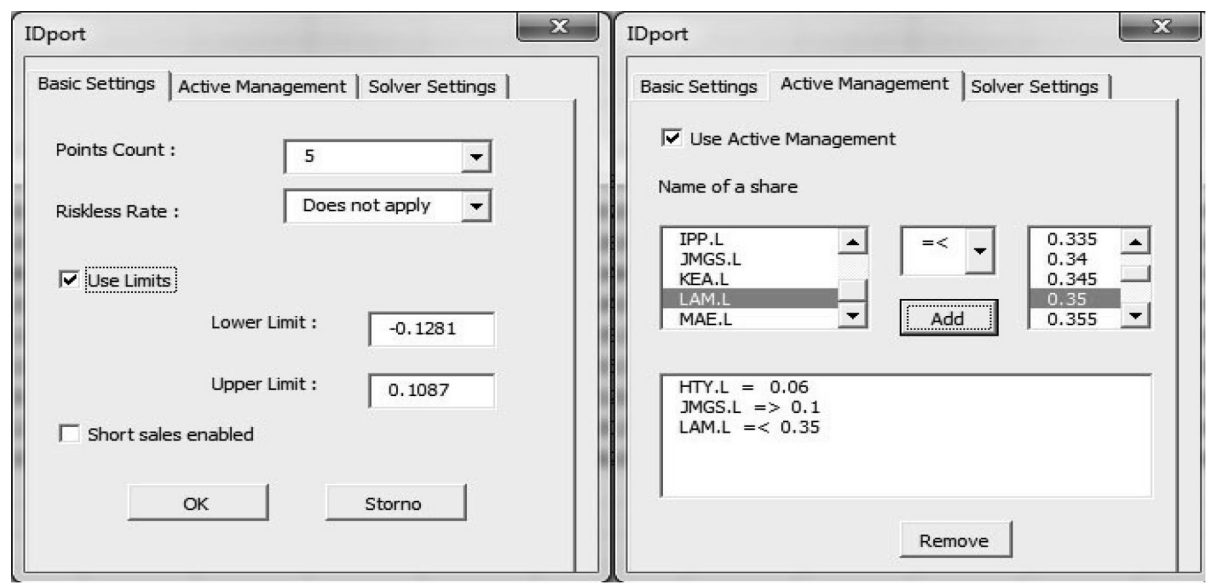

Figure 5. Menu Basic Settings and Active Management

Source: authors' software.

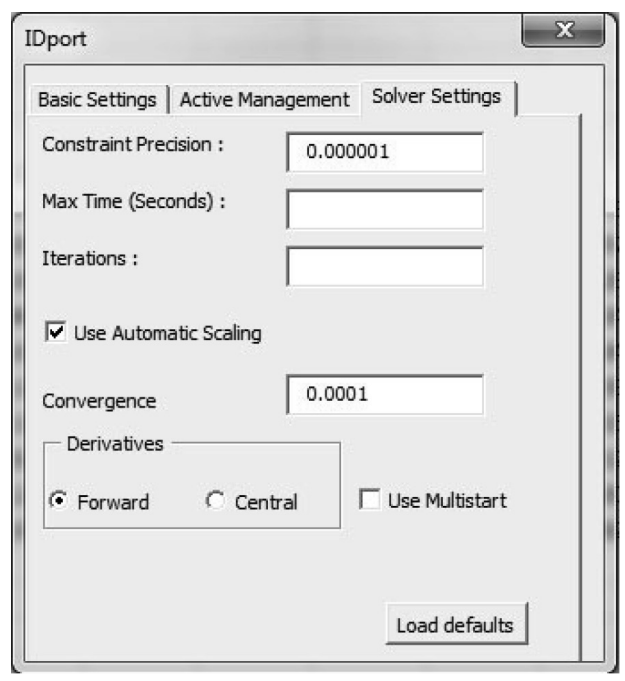

Figure 6. Menu Solver Settings

Source: authors' software. 


\subsection{FINV software manual}

FINV is an application which does not use solver library. It solves nonlinear programming tasks just by using matrix algebra. The tasks were derived just for enabled short sales and that is why FINV works only with the enabled short sales. It also does not contain Active Management. It uses the same sheets as IDPORT. The menu is different and much simpler. The user sets just the number of points which will create the border of investment opportunities and the riskless rate. The user can also zoom into particular part of the border of investment opportunities by means of the Use limits option.

We would like to show a small curiosity in the Results sheet. It is about how tricky finding of the tangency portfolio is. This is what Figure 8 shows. If the global minimum variance portfolio has the expected return smaller than the riskless rate, then the tangency portfolio has a negative Sharpe's slope. A is a tangency portfolio which was selected as a maximum Sharpe's ratio from all the calculated portfolios. B is a tangency portfolio derived from (2). B has a negative slope and this is of course correct. $\mathbf{C}$ represents the values of the global minimum variance portfolio.

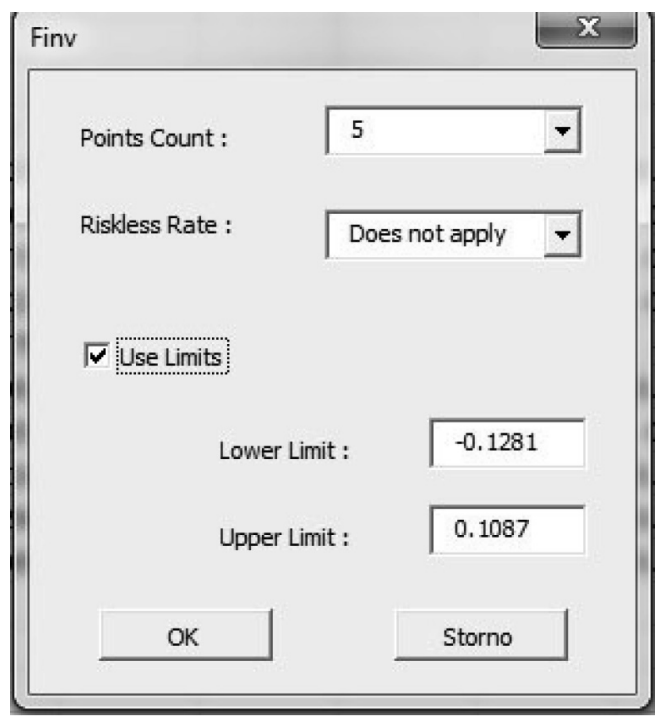

Figure 7. Menu of FINV software

Source: authors' software. 


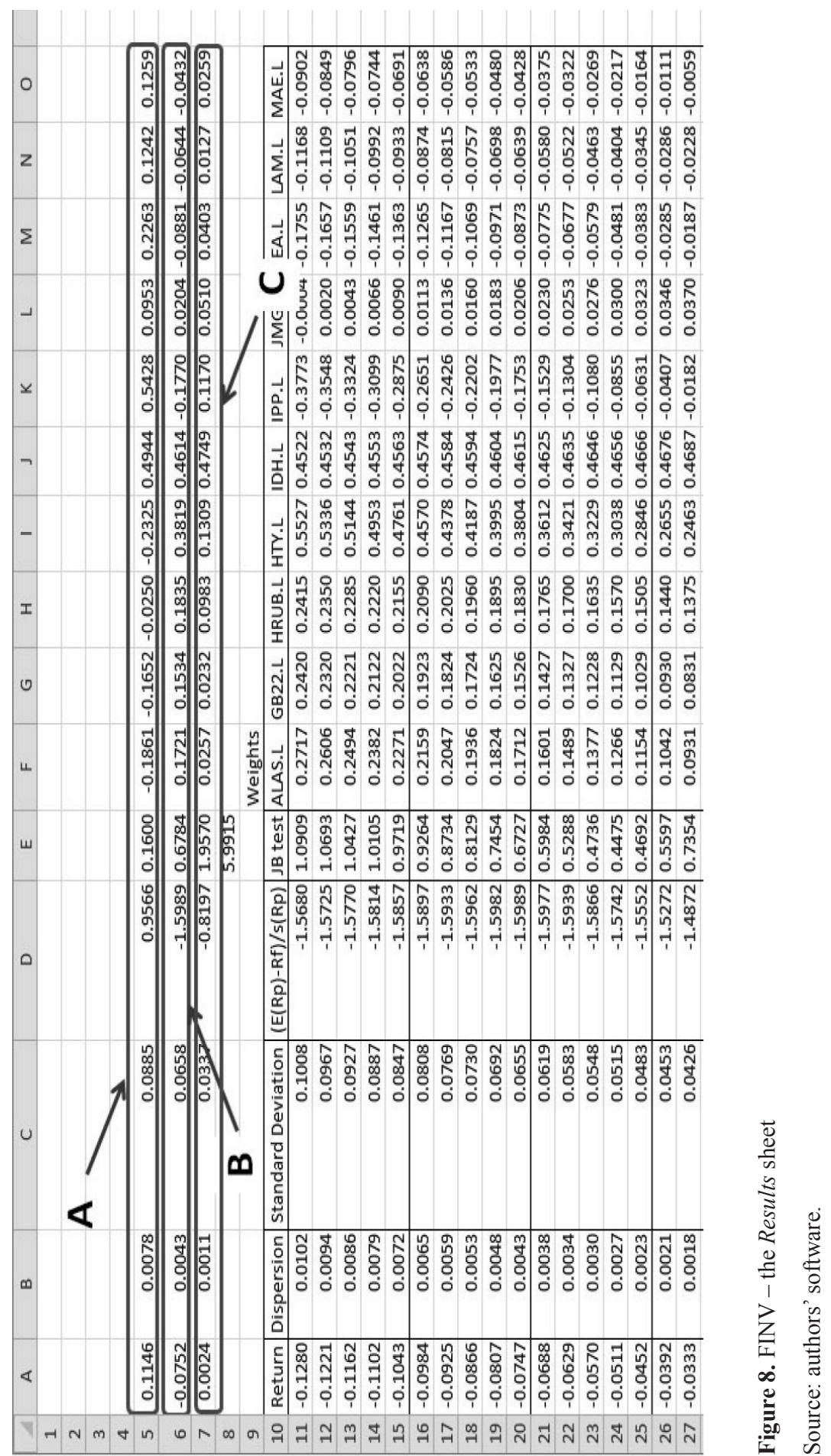




\subsection{Software settings}

IDPORT needs the SOLVER library which is a part of Excel. IDPORT works with the SOLVER library in the version for Excel 2010. It does not work with the previous versions of Excel. The user has to add the SOLVER library manually before opening the IDPORT worksheet. The user has to also enable macros after opening the IDPORT worksheet. There is also something very important in successful using IDPORT. The user has to change system decimal separator to point (.). Changing the decimal separator just in Excel is not sufficient. That setting takes place in the Control Panel in the Region and Language option. FINV does not use the SOLVER library and that is why it works also in Excel 2007. Both applications were not tested in Excel 2013 but they should work also with this Excel version.

\section{Creating a sample portfolio}

Table 1 shows the returns of Johnson \& Johnson (JNJ), AT\&T (T) and IBM (IBM) in the quarter of the year basis for the period 2010-2013. We used adjusted close price because it accounts for stock splits and dividends.

Table 1. Adjusted close returns for JNJ, T and IBM

\begin{tabular}{|c|c|c|c|c|}
\hline Year & & JNJ & T & IBM \\
\hline 2010 & $1 \mathrm{q}$ & -0.010 & -0.034 & 0.041 \\
\hline \multirow{5}{*}{2011} & $2 \mathrm{q}$ & -0.002 & 0.040 & -0.077 \\
\cline { 2 - 5 } & $3 \mathrm{q}$ & 0.105 & -0.046 & -0.033 \\
\cline { 2 - 5 } & $4 \mathrm{q}$ & 0.162 & 0.090 & 0.002 \\
\hline \multirow{3}{*}{2012} & $1 \mathrm{q}$ & 0.053 & 0.019 & 0.048 \\
\hline \multirow{3}{*}{} & $2 \mathrm{q}$ & 0.032 & -0.077 & -0.003 \\
\cline { 2 - 5 } & $3 \mathrm{q}$ & 0.074 & 0.167 & -0.050 \\
\cline { 2 - 5 } & $4 \mathrm{q}$ & -0.004 & 0.135 & 0.079 \\
\hline & $1 \mathrm{q}$ & 0.033 & 0.018 & 0.047 \\
\cline { 2 - 5 } & $2 \mathrm{q}$ & 0.003 & 0.017 & 0.020 \\
\cline { 2 - 5 } & $3 \mathrm{q}$ & -0.006 & -0.047 & 0.071 \\
\hline \multirow{3}{*}{2013} & $4 \mathrm{q}$ & 0.110 & 0.147 & 0.057 \\
\hline \multirow{3}{*}{} & $1 \mathrm{q}$ & -0.054 & -0.021 & 0.133 \\
\cline { 2 - 5 } & $2 \mathrm{q}$ & 0.108 & 0.115 & 0.124 \\
\cline { 2 - 5 } & $3 \mathrm{q}$ & -0.088 & 0.013 & 0.000 \\
\cline { 2 - 5 } & $4 \mathrm{q}$ & 0.031 & 0.044 & 0.059 \\
\hline
\end{tabular}

Source: www.finance.yahoo.com. 
We used 10 years US treasury bonds return as the risk free rate. This rate was at the level of $2.668 \%$ on February 1, 2014. This information was taken from Yahoo finance.

We applied FINV to the data. The computed basic statistics for the shares are described in Table 2.

Table 2. Basic characteristics of JNJ, T and IBM

\begin{tabular}{|l|c|c|c|c|c|c|c|c|}
\hline $\begin{array}{c}\text { Name } \\
\text { of the } \\
\text { shares }\end{array}$ & Return & Dispersion & $\begin{array}{c}\text { Standard } \\
\text { Deviation }\end{array}$ & VaR 0.01 & VaR 0.05 & VaR 0.10 & $\begin{array}{c}\text { Jarque } \\
\text {-Bera }\end{array}$ & $(E(R)-R f) / S(R)$ \\
\hline JNJ & 0.0341 & 0.0043 & 0.0656 & -0.1186 & -0.0738 & -0.0500 & 0.3154 & 0.1134 \\
\hline T & 0.0362 & 0.0056 & 0.0751 & -0.1385 & -0.0873 & -0.0600 & 1.1703 & 0.1261 \\
\hline IBM & 0.0325 & 0.0034 & 0.0579 & -0.1022 & -0.0628 & -0.0417 & 0.3389 & 0.0998 \\
\hline
\end{tabular}

Source: FINV output using the data from www.finance.yahoo.com.

All the shares are normally distributed with expected returns from $3.25 \%$ to $3.62 \%$. All the VaRs are from the one-dollar investment. The best Sharpe's ratio has AT\&T, which is 0.1261 .

Table 3 shows basic characteristics for the tangency portfolio - row 1 and for global minimum variance portfolio - row 2. Johnson \& Johnson weight is $32.94 \%$ for the tangency portfolio and $35.69 \%$ for the global minimum variance portfolio. Both portfolios have almost the same expected return 3.39\% and 3.36\%. Both portfolios are normally distributed. Figure 9 shows the border of the investment opportunities for enabled short sales.

Table 3. The tangency portfolio and global minimum variance portfolio

\begin{tabular}{|c|c|c|c|c|c|c|c|}
\hline Return & Dispersion & $\begin{array}{c}\text { Standard } \\
\text { Deviation }\end{array}$ & $(E(R p)-R f) / s(R p)$ & JB test & JNJ & T & IBM \\
\hline 0.0339 & 0.0017 & 0.0406 & 0.1783 & 0.7258 & 0.3194 & 0.2533 & 0.4273 \\
\hline 0.0336 & 0.0016 & 0.0395 & 0.1734 & 0.1584 & 0.3569 & 0.1314 & 0.5118 \\
\hline
\end{tabular}

Source: FINV output using data from www.finance.yahoo.com

Let us assume that an analyst has decided to back AT\&T company and increase the weight to at least $40 \%$. We used IDPORT application for this purpose. We left short sales enabled.

Table 4. The tangency portfolio for AT\&T at the level of at least $40 \%$

\begin{tabular}{|c|c|c|c|c|c|c|c|}
\hline Return & Dispersion & $\begin{array}{c}\text { Standard } \\
\text { Deviation }\end{array}$ & $(E(R p)-R f) / s(R p)$ & JB test & JNJ & T & IBM \\
\hline 0.0343 & 0.0019 & 0.0440 & 0.1736 & 1.2533 & 0.2263 & 0.4000 & 0.3737 \\
\hline
\end{tabular}

Source: IDPORT output using data from www.finance.yahoo.com. 


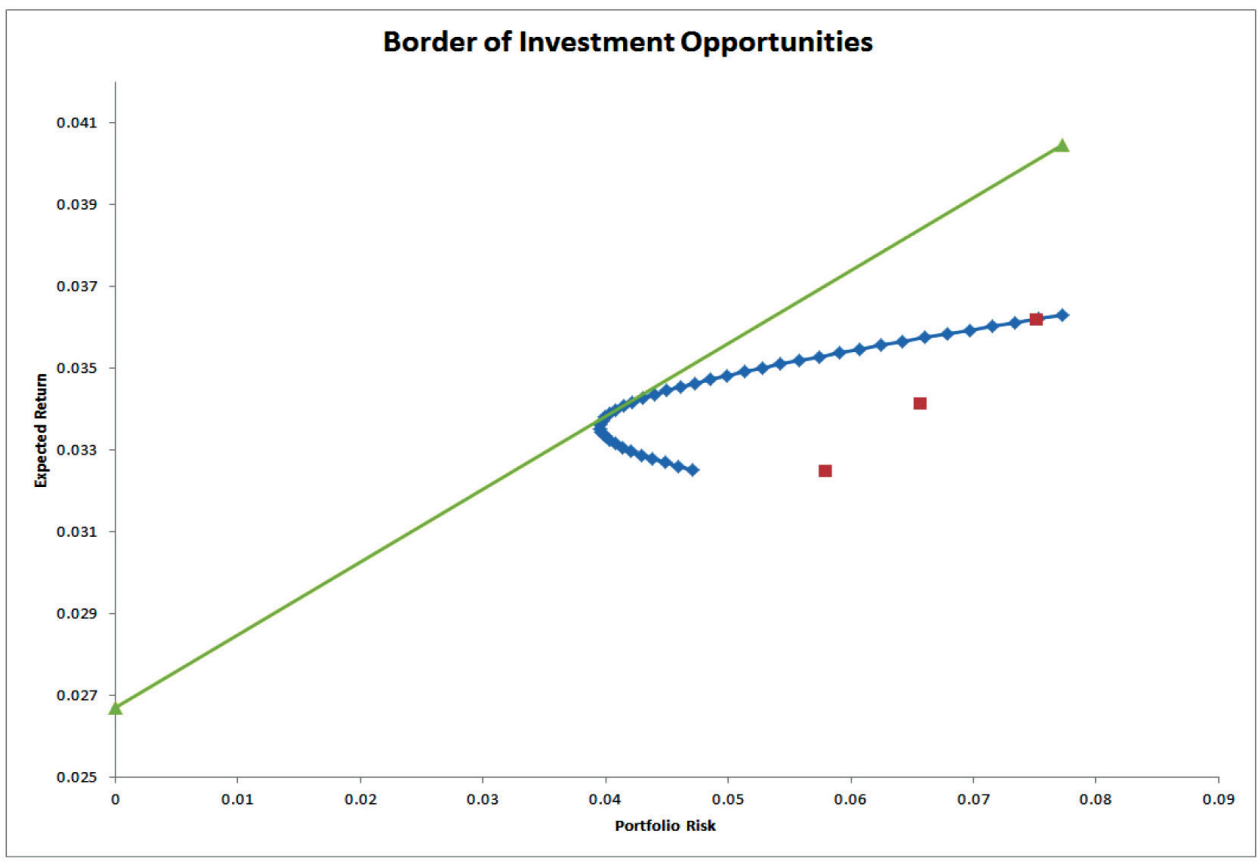

Figure 9. Border of investment opportunities

Source: FINV output using data from www.finance.yahoo.com.

As can be seen, both the expected return and the risk increased, whereas the Sharpe's ratio decreased. Active management has a lot to do with analyst's intuition and preferences.

\section{Conclusion}

Cash management and financial liquidity decisions in the context of their typical interconnections are close to the portfolio investment problem. We have tried to develop the software for portfolio selection modelling. This is just the beginning of the development. A lot of things can be added. The software is mostly suitable for teaching purposes at this stage of the development. We left source codes unlocked so that junior analysts can read the code and discover all the details of coding and learn a lot. Our ambition is to continue developing the application. We would like to add many other pieces of the theory of the investment portfolio to our application in the future. Further studies should be concentrated on the practical experience of using our model in various problems solved in financial management, not only in portfolios of liquid assets like cash, inventories and accounts receivables in enterprises with a full operating cycle. 


\section{References}

Brigham E.F., Ehrhardt M., 2013, Corporate Finance: A Focused Approach, Cengage Learning.

Elton E.J., Gruber M.J., 2007, Modern Portfolio Theory and Investment Analysis, Wiley.

Harrington D.R., 1987, Modern Portfolio Theory, The Capital Asset Pricing Model and Arbitrage Theory: A User's Guide, Prentice-Hall.

Keynes J., 1936, The General Theory of Employment, Interest and Money, Harcourt Brace, London.

Markowitz H., 1997, Portfolio Selection - Efficient Diversification of Investment, Wiley, New York.

McCutcheon J.J., Scott W.F., 1993, An Introduction to the Mathematics of Finance, Oxford.

Michalski G., 2014, Value-Based Working Capital Management. Determining Liquid Asset Levels in Entrepreneurial Environments, Palgrave Macmillan, New York.

Michalski G., 2012, Financial Liquidity Management in Relation to Risk Sensitivity: Polish Enterprises Case, Quantitative Methods in Economics, Vydavatelstvo EKONOM, Bratislava, pp.141-160.

Mlynarovič V., 2001, Financial investment, theory and practice - finančné investovanie: teórie a aplikácie, IURA EDITION, Bratislava.

www.mpavlik.net

\section{DOBÓR SKŁADOWYCH PORTFELA AKTYWÓW BIEŻĄCYCH Z UŻYCIEM OPROGRAMOWANIA}

Streszczenie: Autorzy stworzyli oprogramowanie działające w środowisku Visual Basic. Celem oprogramowania jest pomoc małym inwestorom, którzy zamierzają utworzyć własne portfele inwestycyjne. Autorzy pozostawili kody programu odblokowane w celu umożliwienia badaczom i analitykom zrozumienia szczegółów kodu. Artykuł zawiera także przykład portfela.

Słowa kluczowe: teoria portfelowa, VBA, ryzyko, płynność, zwrot, odchylenie standardowe, statystyki Jarque-Bera. 